Canadian Journal of Family and Youth, 14(1), 2022, pp. 270-275

ISSN 1718-9748(C) University of Alberta

http://ejournals, library, ualberta.ca/index/php/cjfy

\title{
Garrison, Gary. (2018). Raising Grandkids: Inside Skipped Generation Families. Regina: University of Regina Press.
}

Reviewed by: Sashwat Adhikari, MacEwan University

Gary Garrison's book, "Raising Grandkids: Inside Skipped Generation Families”, is an eyeopening, uplifting text that explores the issues of unsupportive child welfare systems, particularly in the domain of parenting in skipped-generation families. This book aims to acknowledge the many situations and difficulties of grandparents who are caregivers for their grandchildren and greatgrandchildren, whilst offering these caregivers a voice, practical help, and ultimately a community who understands. Nevertheless, this book also identifies "the challenges, suffering, joys, sacrifices, and successes [these caregivers] experience in this retirement activity called grandparenting," to uplift and affirm the unique advantages of skipped-generation parenting (p. xii). Garrison initially explores these topics surrounding grandparent-headed households through personal observations. He illustrates his own experience of raising his step-grandchildren and his perspectives on the relationship between support systems and skipped-generation families such as his own. Garrison then sets out to broaden the understanding of this phenomenon by interviewing grandparent caregivers in similar kinship situations. Across his own personal observations and the interviews (oral histories), many similarities arise which allows Garrison to form a supportive educational thread for this caregiver community. Garrison identifies that there are challenges faced by skippedgeneration kinships which are unrelieved by support systems and that social fear ultimately reduces these caregivers' ability to speak up about these struggles. The qualitative interviews that Garrison conducts with other grandparents in similar kinship situations bring about three central themes to 
further understand the unique dynamics of these households. In the book, Garrison focuses on family trauma, unique familial challenges on children, and the phenomenon of providing a voice to these brave caregivers.

Garrison's exploration of these themes in the book serves as an uplifting voice for those who cannot speak up and this is further reinforced by the numerous resources and strategies he provides for these caregivers. These themes and related resources are thoroughly discussed over sixteen, thoughtful chapters throughout the book.

Garrison's own personal experience with the subject matter greatly strengthens the overall cohesion of the discussions and oral histories presented in the book. Garrison is no stranger to this world as he brings insights from being a skipped-generation parent himself - raising his partner's grandchildren. It is certain that his personal insights ultimately strengthen the book to a deeper degree than if a researcher without firsthand experience were to write about these unique kinship situations. Garrison suggests that grandparents in these situations tend to stay quiet on this matter to avoid social consequences and avoid alienating their children. One may beg the question: Why then did these subjects agree to sharing their stories? It is likely that these grandparents saw Garrison as someone who echoes their own life circumstances, allowing them to converse about grandparenting on a more comfortable and relatable level. Garrison shows understanding and respect for their more forthcoming nature in these interviews by using pseudonyms for everyone throughout the book. Additionally, Garrison includes his own grandparenting resources for support to further reinforce the urgency of this issue in child welfare.

Through many oral histories, Garrison highlights the many complicated family dynamics that result in a grandparent having to become a caregiver for their grandchildren and greatgrandchildren. Garrison suggests that grandparents "raise them because their biological parents- 
[their] children - can't or won't, whether because of addiction, mental or physical illness, death, imprisonment, poverty, or marriage breakup" (p. 3). Garrison keeps this phenomenon of family trauma being a precursor relatively constant as he provides insight into the question: Why do skipped-generation families form? To express this in a grand sense, Garrison focuses on Indigenous families' oral histories as they have been majorly affected by intergenerational systemic policies that have led to many complicated family dynamics. Garrison uses the fact of a "disproportionate numbers of Indigenous children in our child welfare systems today" to portray these grandparents as saviors of family and tradition more than anything else (p. 6). Ultimately, Garrison portrays these caregivers in skipped-generation families as unsung heroes of family traumas more than just the common "retired grandparent" (p. 59).

Garrison focuses on the unique familial challenges in skipped-generation households and the effect that it has on children. Notable focus is given to the challenges such as Attention Deficit Hyperactivity Disorder (ADHD), Fetal Alcohol Spectrum Disorder (FASD), and Oppositional Defiant Disorder (ODD) (pp. 10-11). Garrison includes tragic oral histories of children being born with or facing these challenges because of their biological parents. As a result, Garrison uses this theme to further reinforce the importance of skipped-generation caregivers in making sure children are still being protected. Garrison acknowledges this role as he suggests that grandparents ultimately aid in keeping these children out of foster care and adoption. Ultimately delving into the question: "Which is the better way to raise children when the parents can't or won't: Kincare or foster care?" (p. 82). Additionally, in doing this, Garrison provides these insights whilst making sure to avoid throwing shade or blame onto the parents affected by varying circumstances and maintaining a manner of respect. 
In addition to the focus on complicated family dynamics and their effects on children, Garrison also focuses on giving a voice to this community of grandparents. Garrison is sure to acknowledge the challenges faced by these caregivers whilst also addressing how unsupportive systems have not relieved these issues. Consequently, these grandparents live in fear of speaking up due to social consequences that could harm their family. Garrison uses this book as an opportunity to echo his own life experiences along with others' and build a public collective voice on this subject matter.

Filled with numerous oral histories and personal experiences, all delving into the phenomenon of unsupportive systems' effects on skipped-generation families, Garrison's book accomplishes three goals. First, the book offers insight and communicates the urgency of unrecognized issues surrounding skipped-generation families and child-welfare. Second, the book highlights the importance of skipped-generation parenting and offers an optimistic atmosphere in illustrating the benefits of parenting again later in life. Third, the book uses the knowledge of the tensions between these caregivers and support systems to show empathy and support; offering these caregivers an outlet to have their voices heard without fear of social judgment or consequence. Ultimately, this gives them the assurance that they are not alone in facing these kinship challenges. Garrison accomplishes these three goals by gathering themes from oral histories and personally connecting with these caregivers to offer insight, hope, and help in challenges that are unrelieved by so-called child welfare support systems. Additionally, Garrison also uses cohesive writing to remove stigma surrounding skipped-generation families and therefore lessen social judgment towards this community.

Garrison's framework on skipped-generation families in the book encompasses a breadth of thoughts and experiences from other caregivers' oral histories and his own personal observations. 
This collection of information is likely to captivate his intended readership - likely spanning from family sociologists to clinical psychologists, social workers, parents, friends, and grandparents who are trying to understand the dynamics of these kinship situations. Garrison reinforces this as he states how "[he has] to develop a support network" of "[friends and family members who will support, share experiences, commiserate with, and suggest options to]" grandparents that are caregivers (p. xiv). This book can essentially be used as an asset to any professional audience working with families and children. For instance, anthropologists, family lawyers and counsellors can also be grouped in Garrison's intended audience as the book can give them an in-depth understanding of family dynamics in skipped-generation households.

Additionally, another intended audience of this book can be seen as skipped-generation caregivers themselves. This book can be used by struggling grandparents to find sources of hope, optimism, and self-love in their own journey of grandparenting. This audience can use these oral histories and Garrison's personal observations to relate and feel a sense of pride and accomplishment rather than fear of scrutinization and social judgment.

Garrison does an excellent job of forming cohesive discussions between his own life and other grandparents that are also in skipped-generation households. Garrison effectively communicates the underlying issues in this field and acknowledges the value of skipped- generation caregivers through a professional yet personal measure of study. I found his ability to personally relate to the subject matter as an advantage in providing a more attached understanding of skippedgeneration families. Furthermore, I found much respect and bravery in Garrison's candor, as well as the honesty and vulnerability portrayed in the oral histories throughout the book. It could be said that some of the oral histories presented in the book are quite triggering and difficult to read through. This could be seen as a potential limitation of the book as certain audiences could find these stories 
more provoking and triggering than educational. Despite this, I understand that these stories were necessary to effectively discuss the themes surrounding skipped-generation families and to fully engage the audience into the topic. I found "Raising Grandkids: Inside Skipped Generation Families" a captivating, easy to follow book and would recommend it to anyone interested in the topic of family, children, and kincare. 